University of Nebraska - Lincoln

DigitalCommons@University of Nebraska - Lincoln

Publications, Agencies and Staff of the U.S.

Department of Commerce

U.S. Department of Commerce

2011

Oceanographic coupling across three trophic levels shapes source-sink dynamics in marine metacommunities

\author{
J. Wilson White \\ University of North Carolina - Wilmington, whitejw@uncw.edu \\ Jameal F. Samhouri \\ NOAA Fisheries
}

Follow this and additional works at: https://digitalcommons.unl.edu/usdeptcommercepub

Part of the Environmental Sciences Commons

White, J. Wilson and Samhouri, Jameal F., "Oceanographic coupling across three trophic levels shapes source-sink dynamics in marine metacommunities" (2011). Publications, Agencies and Staff of the U.S. Department of Commerce. 327.

https://digitalcommons.unl.edu/usdeptcommercepub/327

This Article is brought to you for free and open access by the U.S. Department of Commerce at DigitalCommons@University of Nebraska - Lincoln. It has been accepted for inclusion in Publications, Agencies and Staff of the U.S. Department of Commerce by an authorized administrator of DigitalCommons@University of Nebraska - Lincoln. 
Oikos 120: 1151-1164, 2011

doi: $10.1111 / j .1600-0706.2010 .19226 . x$

No claim to original US government works. Oikos (C) 2011 Nordic Society Oikos

Subject Editor: Dustin Marshall. Accepted 24 November 2010

\title{
Oceanographic coupling across three trophic levels shapes source-sink dynamics in marine metacommunities
}

\author{
J. Wilson White and Jameal F. Samhouri
}

J.W. White (whitejw@uncw.edu), Dept of Wildlife, Fish, and Conservation Biology, Univ. of California, Davis, Bodega Marine Laboratory, PO Box 247, Bodega Bay, CA 24923, USA. Present address: Dept of Biology and Marine Biology, Univ. of North Carolina, Wilmington, 601 S. College Rd, Wilmington, NC 28403, USA. - J. F. Samhouri, Pacific States Marine Fisheries Commission, 205 SE Spokane St, Suite 100, Portland, OR 97202, USA, and: NOAA Fisheries, Northwest Fisheries Science Center, 2725 Montlake Blvd E, Seattle, WA 98112, USA.

\begin{abstract}
A central goal of metapopulation ecology is to determine which subpopulations have the greatest value to the larger metapopulation. That is, where are the 'sources' that are most essential to persistence? This question is especially relevant to benthic marine systems, where dispersal and recruitment are greatly affected by oceanographic processes. In a single-species context, theoretical models typically identify 'hotspots' with high recruitment, especially high self-recruitment, as having the highest value. However, the oceanographic forces affecting larval delivery of a given species may also influence the recruitment of that species' predators, prey, and competitors. We present evidence from the Virgin Islands and Bahamas that oceanographic forces produce spatial coupling between the recruitment of planktivorous fishes, the recruitment of their predators, and the productivity of their zooplankton prey. We examined the consequences of this type of multi-trophic coupling using a simple analytical population model and a multispecies numerical simulation model with parameter values based on the Virgin Islands system. In both analyses, strong coupling caused planktivores at the highest recruitment sites to experience higher mortality (a consequence of higher predator densities) but faster growth and higher fecundity (a consequence of higher zooplankton densities) than planktivores at low recruitment sites. As such, the relative strength of oceanographic coupling between the three trophic levels strongly determined whether a particular reef acted as a source or sink. In the simulation model, density-dependent competition for zooplankton limited overall metapopulation biomass more severely than predation, so oceanographic coupling between planktivore larval supply and zooplankton productivity had a stronger effect on the metapopulation value of a patch. We argue that the potential for such tri-trophic coupling should be incorporated into future metacommunity models and has considerable implications for the design and evaluation of marine reserves.
\end{abstract}

Many species exist in metapopulations in which patchily distributed local populations are connected by long-distance dispersal across inhospitable territory. Habitat patches in which local populations occur may arise naturally (as in the archipelagos typical of marine reef systems; Kritzer and Sale 2006) or as the result of anthropogenic perturbations such as habitat destruction and fragmentation (Hanski and Gilpin 1991). In either case, two major goals of metapopulation ecology are to identify individual patches that will sustain larger local populations of a particular species and to determine which patches are most critical to the persistence of the entire metapopulation (Ovaskainen and Hanski 2003, Figueira 2009). Both goals are related to quantifying the value of a patch to the metapopulation, though these two aspects of value are distinct: critical patches need not have large populations, and vice versa (White 2008).

Two key factors structuring patch value for a consumer species are (1) the availability of prey resources and (2) the abundance of natural enemies in each patch (Figueira and Crowder 2006, White 2008). Though many metapopulation studies assume that demographic rates are the same among all patches, spatial heterogeneity in rates of competition and predation has long been known to generate variation in vital rates among local populations (Menge et al. 2004, reviewed by Holt 1997). Such spatial heterogeneity usually depends on the rates of movement of different species among patches (Leibold et al. 2004). Other factors such as interspecific competition and habitat quality may also influence patch value, but we do not address those factors here.

The factors determining movement rates among patches can differ dramatically between terrestrial and aquatic metapopulations. For instance, on land predators and prey engage in a habitat selection 'game' that usually results in prey equalizing predation rates or predators equalizing per capita consumption rates over space (Sih 2005). In freshwater and marine systems, physical forcing by currents can overwhelm such behaviorally directed movements of predators and prey (Power and Dietrich 2002, Cowen and Sponaugle 2009). However, physical forcing will not necessarily cause interacting species to be randomly distributed with respect to one another. On the contrary, the movement of interacting species among patches in aquatic metacommunities is quite 
likely to be shaped by similar sets of physical forces, which may cause spatial covariation of their abundances (Leichter et al. 1998, White 2007, 2008, Hilker and Lewis 2010).

In marine reef systems, physical forces can affect the dynamics of small-bodied planktivorous fishes (e.g. damselfishes, wrasses), the zooplanktonic resources (e.g. copepods) upon which the planktivores forage, and the larger-bodied piscivorous fish species (e.g. groupers, snappers and jacks) that prey upon the planktivores. Consequently, coastal oceanographic forces could lead to a spatial coupling of the dynamics and abundance of these three trophic groups (plankton, planktivores and predators) across patches within the metacommunity. In this context, we consider habitat patches to be individual coral reefs (on the order of $10^{3}$ to $10^{5} \mathrm{~m}^{2}$ in area) that are isolated by areas of non-reef habitat or by the spatially restricted movement of reef organisms (a 'functional' metacommunity, sensu Kritzer and Sale 2006, White 2007). Empirical data are seldom collected at a spatial scale large enough to test for such patterns, but compelling evidence for this three-way coupling comes from St. Croix, US Virgin Islands and the Exuma Cays, Bahamas.

In St. Croix, the densities of planktivorous bluehead wrasse Thalassoma bifasciatum recruits, recruits of its primary predator the coney grouper Cephalopholis fulva, and its preferred food resource, cyclopoid copepods, are positively correlated and highest on the northwest shore (Fig. 1; White 2007, White and Warner 2007a). This pattern is likely due to the accumulation of larvae and zooplankton in nearshore waters as a result of current convergence and decreased transport due to slow currents at that site (Harlan et al. 2002, Hamilton et al. 2006). In the Bahamas, the densities of planktivorous bicolor damselfish Stegastes partitus and resident piscivorous fishes (families Serranidae, Synodontidae and Aulostomidae), and the biomass of the damselfish's preferred zooplanktonic food resource show a pattern similar to that in St. Croix (Fig. 2; Samhouri 2007). The highest plankton-planktivore-predator densities occur at sites with the highest delivery rates via strong flood tides fed by the waters of Exuma Sound, the most probable source of nutrients, plankton, and fish larvae (Thorrold et al. 1994b; see Lipcius et al. 1997 for a description of oceanography in the area).

This type of covariation across trophic levels may be common in reef systems. Convergence regions like that in St. Croix and other oceanographic features (e.g. island wakes and eddies) can promote the retention of locally spawned fish larvae and entrainment of larvae spawned elsewhere, leading to predictable heterogeneity among reefs in rates of larval settlement (Thorrold et al. 1994a, Sponaugle and Cowen 1997). Indeed, such oceanographic features can create 'hotspots' of high settlement for multiple species occupying different trophic levels (White 2007). This covariation in settlement likely arises because many fish species are characterized by similar seasonality in spawning, pelagic larval duration, and
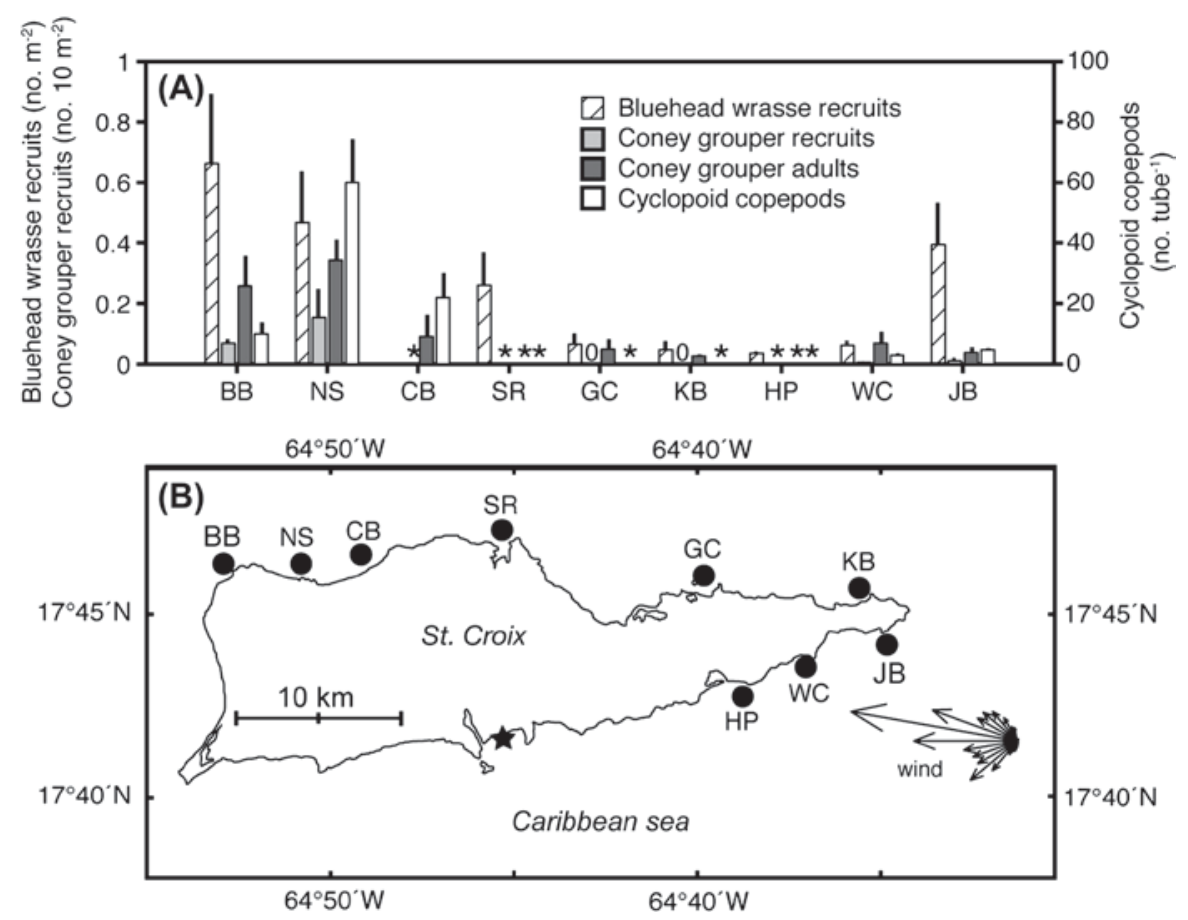

Figure 1. Empirical evidence for tri-trophic oceanographic coupling from St. Croix, US Virgin Islands. (A) Mean density of recruits of the planktivorous bluehead wrasse Thalassoma bifasciatum, recruits and adults of the coney grouper Cephalopholis fulva, a major bluehead wrasse predator, and planktonic cyclopoid copepods, the primary component of the bluehead wrasse diet, at sites around St. Croix. Error bars are 1 SE. Stars indicate no data were available; zeroes indicate absence of a particular group at a site. (B) Map of St. Croix showing location of study sites. Rosette indicates distribution of wind directions in February-December 2005. Length of arrows indicates frequency of occurrence, not velocity; wind data collected at NOAA National Ocean Service station LTBV3 (location indicated by star on map; URL: <www. nbdc.noaa.gov $>$ ). Butler Bay $=$ BB, Northstar $=$ NS, Cane Bay $=$ CB, Salt River $=$ SR, Green Cay $=$ GC, Tague Bay $=$ TB, Knight Bay $=$ KB, Ha'penny = HP, Wood Cottage $=$ WC, Jacks Bay = JB. Data from Hamilton et al. (2006), White (2007) and White and Warner (2007a, b); see Supplementary material Appendix 1 for details on data collection and sample size. 

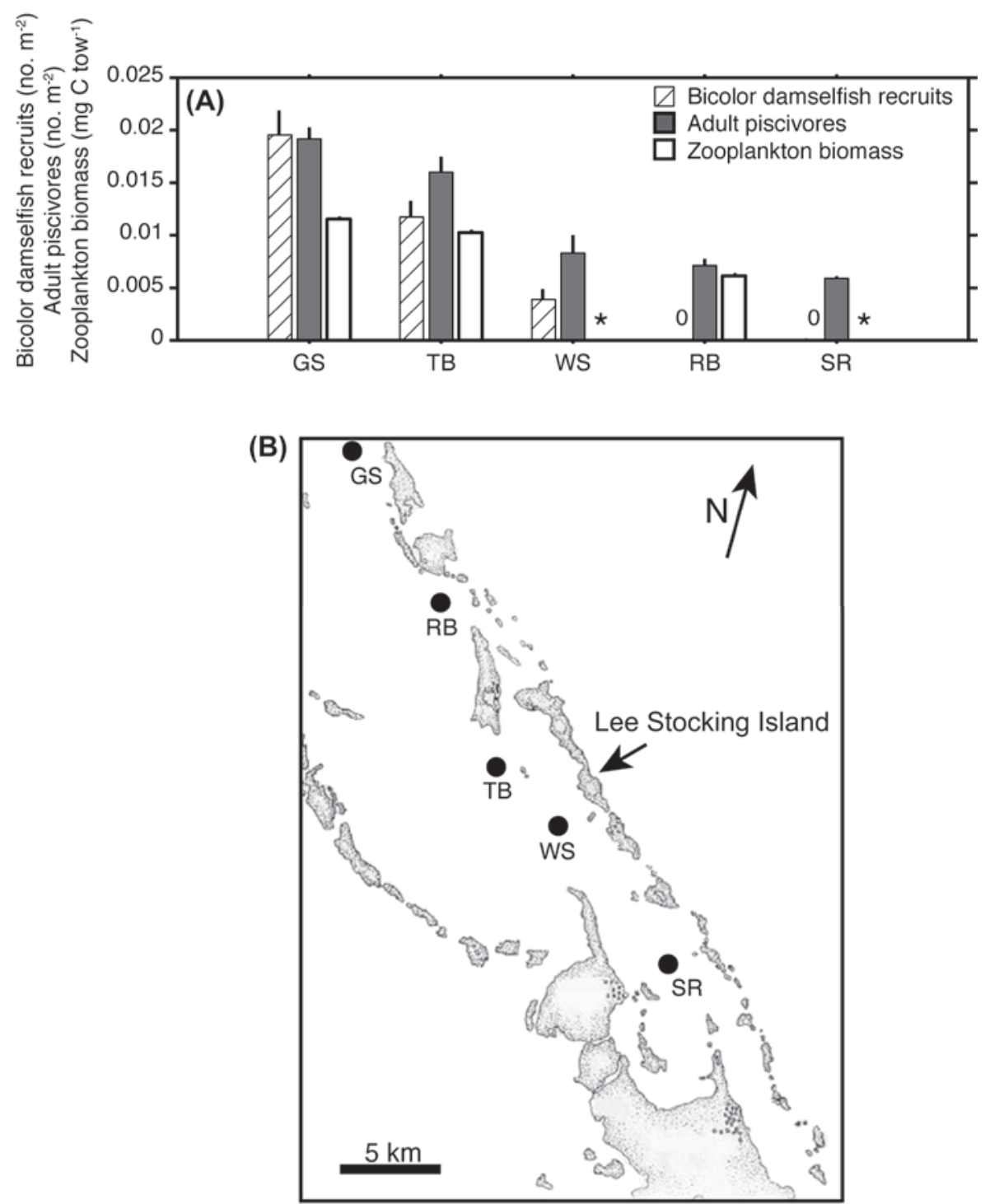

Figure 2. Empirical evidence for tri-trophic oceanographic coupling from Exuma Bank, Bahamas. (A) Mean density of recruits of the planktivorous bicolor damselfish Stegastes partitus, recruits and adults of groupers, lizardfish, and trumpetfish (major predators of bicolor damselfish), and biomass of zooplankton, the primary component of the bicolor damselfish diet, at sites on Exuma Bank. Error bars are 1 SE. Stars indicate no data were available, whereas zeroes indicate absence of a particular group at a site. (B) Map of Exuma Bank showing location of study sites. Goby Spot $=\mathrm{GS}, \mathrm{TB}=$ Tug and Barge, WS $=$ Windsock, RB = Rainbow, SR $=$ Square Rock. Data from Samhouri (2007); see Supplementary material Appendix 1 for details on data collection and sample size.

larval body size, which presumably affects swimming ability (Sale 1991). The same physical forcing mechanisms that retain fish larvae can create areas of relatively high phytoplankton productivity, and ultimately, high zooplankton productivity and retention (Hamner et al. 1988, Wolanksi and Hamner 1988). As a result, reefs near large-scale oceanographic retention features should not only be characterized by greater rates of larval fish settlement, but also by greater availability of zooplankton food resources (Leichter et al. 1998, Carleton et al. 2001, Hamner et al. 2007).

The metapopulation-level consequences of oceanographically-forced coupling like that seen in St. Croix and the Bahamas are difficult to predict a priori. A high degree of coupling between predator and prey settlement can lead to higher and more strongly density-dependent prey mortality at highsettlement sites (White 2007), reducing prey population density and thus total reproductive output at those sites (White 2008). By contrast, oceanographic coupling between planktivores and their prey can lead to faster planktivore growth at high-settlement sites (White and Warner 2007a) and can boost per capita reproductive output (Samhouri 2009). In order to quantify our expectations for the relative effects of oceanographic coupling among the three trophic groups, we derived a simple analytical model to explore the effects of different coupling strengths on the biomass abundance of the planktivore population. We then present a more realistic simulation model of a coral reef metacommunity which reveals the complex effects of oceanographic coupling on the metapopulation dynamics of the planktivore. The models also allow us to evaluate the relationship between predator-prey and planktivore-plankton coupling on patch value within the planktivore metapopulation. While these 
models describe trophic interactions within a metacommunity, we focus on the dynamics and patch value of the planktivore metapopulation. We chose this approach because the concept of patch value has not yet been developed for a full metacommunity (Leibold et al. 2004), and so that this work could serve as a bridge between single-species marine metapopulation efforts and more complex multispecies models.

\section{Analytical model of an open local population}

We begin by constructing a relatively simple continuoustime model of a tri-trophic community. This model provides several analytical expressions that reveal the general consequences of oceanographically-forced coupling across trophic levels for a planktivoruous prey species. However, in order to keep this model tractable we make a variety of simplifying assumptions, such as linear functional responses and no age structure. We then relax many of these assumptions in a more complex numerical model. The latter model contains many of the features considered to be important in marine fish population dynamics (e.g. density-dependent prey mortality, age structure, and gape-limited predation) but has a large number of parameters and can only be analyzed by simulation.

For the analytical model, we focus on three trophic groups, zooplankton $\mathrm{Z}$, planktivores $\mathrm{N}$, and piscivores $\mathrm{P}$, and express their abundances in terms of biomass density. A simple Lotka-Volterra model of the planktivore population biomass at a focal reef is:

$$
\frac{\mathrm{dN}}{\mathrm{dt}}=\eta \mathrm{ZN}-\xi \mathrm{PN}-\mu \mathrm{N}+\sigma \mathrm{S}
$$

where $\eta$ is a compound parameter representing feeding rate and feeding efficiency of $\mathrm{N}$ on $\mathrm{Z}, \xi$ is the predator attack rate, $\mu$ is a metabolic loss rate, and $S$ is the number of arriving settlers which have $\sigma$ units of biomass per individual. We assume that $S$ is a function of the parameter $\phi$, representing transport of larval settlers to the reef by oceanographic processes (see Cowen and Sponaugle 2009 for a discussion of the processes potentially affecting larval transport). For simplicity we scale units so that $S=\phi$. This model represents a fully open subpopulation that has no internal dynamic feedback and is subsidized entirely by external larval supply. While not very realistic, it provides a simple way of examining the consequences of oceanographic coupling across trophic levels.

Rather than model the dynamics of Z and P explicitly, we assume that they are coupled to the same oceanographic process $\phi$ that drives planktivore larval delivery. Following White (2008), we assume that the strength of this coupling is given by the parameter $\pi(0 \leq \pi \leq 1)$, which represents the proportion of local $\mathrm{Z}$ productivity or $\mathrm{P}$ recruitment that is due to $\phi$. The remaining $1-\pi$ of local $Z$ or $P$ is due to some other unrelated, reef-based process $\psi$. Processes represented by $\psi$ could include local habitat complexity (affecting predator densities) or inorganic nutrient availability (affecting zooplankton productivity). Thus the expressions for $\mathrm{Z}$ and $P$ are
$\mathrm{Z}=\kappa_{\mathrm{Z}}\left[\pi_{\mathrm{Z}} \phi+\left(1-\pi_{\mathrm{Z}}\right) \psi_{\mathrm{Z}}\right.$

and

$\mathrm{P}=\kappa_{\mathrm{P}}\left[\pi_{\mathrm{P}} \phi+\left(1-\pi_{\mathrm{P}}\right) \psi_{\mathrm{P}}\right]$

where $\kappa_{\mathrm{Z}}$ and $\kappa_{\mathrm{P}}$ are constants of proportionality.

The equilibrium solution to the analytical model (Eq. 1-3) shows that the equilibrium density of planktivores, $\mathrm{N}^{*}$, is

$$
\mathrm{N}^{*}=\frac{\sigma S}{\mu-\eta Z+\xi P}
$$

Assuming for simplicity that $\phi_{\mathrm{Z}}=\phi_{\mathrm{P}}$ and $\psi_{\mathrm{Z}}=\psi_{\mathrm{P}}$ rewriting Eq. 4 in terms of $\phi$ produces

$$
\mathrm{N}^{*}=\frac{\sigma \phi}{\mu+\phi\left(\xi \kappa_{\mathrm{P}} \pi_{\mathrm{P}}-\eta \kappa_{\mathrm{Z}} \pi_{\mathrm{Z}}\right)+\psi\left[\xi_{\mathrm{P}}\left(1-\pi_{\mathrm{P}}\right)-\eta \kappa_{\mathrm{Z}}\left(1-\pi_{\mathrm{Z}}\right)\right]}
$$

Several patterns emerge from examining this expression. First, because the oceanographic parameter $\phi$ appears in the numerator, planktivore biomass is limited by larval supply and will increase with increasing $\phi$. Likewise, because $\mu$ appears in the denominator, increasing metabolic costs will reduce the planktivore population biomass. To understand how the second and third terms in the denominator influence $\mathrm{N}^{*}$, it is useful to first contextualize the parameters $\pi$, $\psi, \eta \kappa_{\mathrm{P}}$ and $\xi \kappa_{\mathrm{P}}$

In a 'null' metacommunity model, movement rates of the three interacting trophic groups we have modeled are assumed to be independent. Such an assumption is equivalent to setting $\pi_{\mathrm{Z}}=\pi_{\mathrm{P}}=0$ in our model. In that case, $\left[\phi\left(\xi \kappa_{\mathrm{P}} \pi_{\mathrm{P}}-\eta \kappa_{\mathrm{Z}} \pi_{\mathrm{Z}}\right)\right]=0$ as well, so that the third term in the denominator of Eq. 5, $\left[\psi\left[\xi \kappa_{\mathrm{P}}\left(1-\pi_{\mathrm{P}}\right)-\eta \kappa_{\mathrm{Z}}\left(1-\pi_{\mathrm{Z}}\right)\right]\right]$, has a major influence on $\mathrm{N}^{*}$ (note that if $\phi_{Z} \neq \phi_{\mathrm{p}}$ and $\psi_{\mathrm{Z}} \neq \psi_{\mathrm{P}}$, the denominator would have additional terms but the qualitative results would hold). This expression implies that if oceanographic coupling is negligible, and predation has a stronger influence than resource productivity on $\mathrm{N}^{*}\left(\xi \kappa_{\mathrm{P}}\left(1-\pi_{\mathrm{P}}\right)>\eta \kappa_{\mathrm{Z}}\left(1-\pi_{\mathrm{Z}}\right)\right)$, then equilibrium planktivore biomass will be small. Conversely, if the positive effects of resource productivity are stronger than the negative effects of predation $\left(\xi \kappa_{\mathrm{P}}\left(1-\pi_{\mathrm{P}}\right)<\eta \kappa_{\mathrm{Z}}\left(1-\pi_{\mathrm{Z}}\right)\right)$, equilibrium planktivore biomass will be comparatively large. Because predation is thought to be the primary structuring process in coral reef fish communities (Hixon 1991), for the remainder of this treatment we assume that $\xi \kappa_{\mathrm{P}}>>\eta \kappa_{\mathrm{Z}}$. We emphasize that with the null model assumptions, if all other parameters are equal, $\mathrm{N}^{*}$ will increase with $\phi$ (compare the points nearest the origin in Fig. 3a-b; parameter values used for solutions in Fig. 3 given in Supplementary material Appendix 2, Table A1).

Further insight can be gained into Eq. 5 by considering the relative magnitude of prey-linked oceanographic factors $(\phi)$ relative to reef-based factors $(\psi)$ as $\pi_{\mathrm{Z}}$ and $\pi_{\mathrm{P}}$ increase from 0 to 1 . When $\phi$ is greater than $\psi$ (Fig. 3 ), as $\pi_{\mathrm{P}}$ increases the second term in the denominator of Eq. 5 becomes increasingly large. Consequently, increasing predator-planktivore oceanographic coupling (i.e. moving along the vertical axis of Fig. 3) boosts predator effects relative to resource supply effects, causing $\mathrm{N}^{*}$ to decline. This result implies that a null model which ignores significant predator-planktivore coupling $\left(\pi_{\mathrm{P}}>>0\right)$ will overestimate planktivore population 


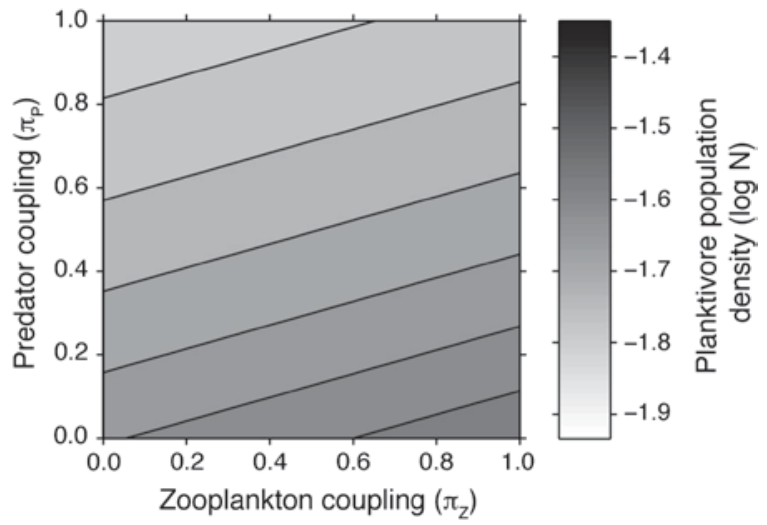

Figure 3. Planktivore population biomass density at equilibrium $\left(\mathrm{N}^{*}\right)$ in the analytical model as a function of oceanographic coupling of predator and prey larval supply $\left(\pi_{\mathrm{p}}\right)$ and planktivore larval supply with plankton flux over the reef $\left(\pi_{\mathrm{Z}}\right)$. The oceanographic process $\phi$ delivering planktivore larvae to the patch is greater than the reef-based factor $\psi$ affecting zooplankton and predator densities $(\phi=0.75, \psi=0.5)$. Other parameter values given in Supplementary material Appendix 2, Table A1.

biomass (White 2008). Similarly, a null model which ignores significant planktivore-plankton coupling $\left(\pi_{\mathrm{Z}}>>0\right)$ will underestimate planktivore population biomass because increasing $\pi_{\mathrm{Z}}$ (i.e. moving along the horizontal axis of Fig. 3) boosts resource supply effects relative to predator effects, causing $\mathrm{N}^{*}$ to increase. The point at which oceanographic coupling due to $\pi_{\mathrm{P}}$ and $\pi_{\mathrm{Z}}$ exactly balance, producing the same $\mathrm{N}^{*}$ prediction as the null model, will depend on the relative magnitudes of $\phi$ versus $\psi$ and versus (note isopleths indicating equal values of $\mathrm{N}$ in Fig. 3). When $\psi>\phi$ (i.e. oceanographic factors are weaker than reef-based factors), these patterns are reversed; for example, when predator larval supply is linked strongly to planktivore larval supply $\left(\pi_{\mathrm{P}}>>0\right)$, predator density $\mathrm{P}$ and the rate of predation on $\mathrm{N}^{*}$ are reduced relative to the no-coupling $\left(\pi_{\mathrm{P}}=0\right)$ scenario (results for $\psi>\phi$ not shown for brevity).

\section{Numerical simulation model of a coupled metacommunity}

The open population model described above requires a number of simplifying assumptions for the sake of analytical tractability. As such, we were concerned that the analytical results would not hold in a demographically closed system with more realistic, nonlinear processes and explicit dynamics for all three trophic levels. To investigate this possibility, we developed a metacommunity model based largely on the copepod-wrasse-grouper metacommunity in St. Croix (Fig. 1; parameter values given in Supplementary material Appendix 2, Table A2.2). This model has more realistic details but cannot be solved analytically, so we examined the results of numerical simulations. Below we describe the dynamics of the planktivore, predator and zooplankton metapopulations (consisting of $i=1,2, \ldots M$ subpopulations) in turn. As we explain and justify below, we consider a system that is tightly linked by physical forces, but not by trophic linkages: there is no dynamic feedback from the planktivore to the generalist predator (because predators consume multiple prey species; Murdoch et al. 2002), nor does the planktivore affect the dynamics of the offshore zooplankton population (because planktivory occurs over the reef). Thus there are no opportunities for a trophic cascade in this system.

\section{Planktivore population}

Motivated by a broad array of empirical studies (synthesized by Osenberg et al. 2002), we assume that arriving planktivore settlers experience (intracohort) density-dependent mortality described by a Beverton-Holt function. After a timestep of one month, which approximates both the pelagic larval duration and the time recent settlers interact primarily amongst themselves before beginning to behave more like adults, settlers recruit into age class 1 of the adult population.

$\mathrm{N}_{\mathrm{t}+1,1, \mathrm{i}}=\left(\frac{\alpha_{\mathrm{N}}}{1+\alpha_{\mathrm{N}} S_{\mathrm{t}} / \beta_{\mathrm{N}}}\right) S_{\mathrm{t}, \mathrm{i}}$

where $\mathrm{N}_{\mathrm{t}, \mathrm{a}, \mathrm{i}}$ is the density of planktivores in age class a at time $t$ in subpopulation $i, S_{t, i}$ is the density of settlers at $i$, and $\alpha_{N}$ is a density-independent survivorship rate. Following White (2007, 2008), we assume that $\beta_{\mathrm{N}}$ (the asymptotic maximum density of planktivore recruits) is inversely proportional to predator density (for convenience we represent the sum of predator density across all age classes as $\hat{\mathrm{P}}_{\mathrm{t}, \mathrm{i}}$ ):

$\beta_{\mathrm{N}}=\kappa_{\mathrm{P}}\left(\hat{\mathrm{P}}_{\mathrm{t}, \mathrm{i}}\right)^{-1}$

Note that the density-dependent mortality described by Eq. 6-7 is assumed to occur over the course of several days after larval settlement. After recruitment, adults experience density-independent mortality that is also a function of predator density:

$\mathrm{N}_{\mathrm{t}+1, \mathrm{a}+1, \mathrm{i}}=\mathrm{N}_{\mathrm{t}, \mathrm{a}, \mathrm{i}} \exp \left(-\left(\delta_{\mathrm{N}}+\xi_{\mathrm{P}} \hat{\mathrm{P}}_{\mathrm{t}, \mathrm{i}}\right)\right)$

where $\delta_{\mathrm{N}}$ is a background mortality rate and $\xi_{\mathrm{P}}$ represents a linear predator attack rate, a reasonable assumption for a generalist fish predator over typical ranges of prey densities (Sandin and Pacala 2005). We assume that large planktivores have a size refuge from gape-limited predators (Wainwright and Bellwood 2002), so for age classes with $\mathrm{L}_{\mathrm{a}}>\mathrm{L}_{\text {gape }}$ (where $\mathrm{L}_{\mathrm{a}}$ is length at age a), $\xi_{\mathrm{P}}=0$.

To describe planktivore biomass dynamics, we assume that planktivores feed exclusively on zooplankton moving across the reef at velocity $\omega$, which (for simplicity) is constant across all reefs (note that $\omega$ describes oceanographic transport at the relatively small scale of the reef; this is independent of the larger-scale transport processes affecting local retention, larval delivery and zooplankton productivity). Assuming $\omega \leq 12 \mathrm{~cm} \mathrm{~s}^{-1}$, the zooplankton density Q available to each planktivore is a linear function of the zooplankton flux $\omega Z$ (units: $g$ zooplankton $\mathrm{m}^{-2} \mathrm{~s}^{-1}$ ) passing through the reactive volume of the planktivore (Kiflawi and Genin 1997, Holzman and Genin 2003) and the cross-sectional area $\gamma_{\omega}$ of the reactive volume, which is inversely proportional to planktivore density (Kent et al. 2006), i.e. planktivores experience intraspecific competition for their zooplanktonic resource (Hamner et al. 1988, Kingsford and MacDiarmid 1988, Jones and McCormick 2002, Persson and De Roos 2006). Combining these two factors yields 


$$
\mathrm{Q}_{\mathrm{t}, \mathrm{i}}=\gamma_{\mathrm{Z} 1} \omega \mathrm{Z}_{\mathrm{t}, \mathrm{i}} \times \gamma_{\omega}=\gamma_{\mathrm{Z}} \omega \mathrm{Z}_{\mathrm{t}, \mathrm{i}} \times \gamma_{\mathrm{Z} 2} \gamma_{\omega 0} \hat{\mathrm{N}}_{\mathrm{t}, 1}^{-1}
$$

where $\gamma_{\omega 0}$ is the value of $\gamma_{\omega}$ at very low planktivore density, $\gamma_{\mathrm{Z} 1}$ and $\gamma_{\mathrm{Z} 2}$ are constants of proportionality and $\hat{\mathrm{N}}_{\mathrm{t}, \mathrm{i}}$ is the total density of all planktivore age classes. Combining constants into a single parameter $\gamma$, we obtain

$$
\mathrm{Q}_{\mathrm{t}, \mathrm{i}}=\gamma \mathrm{Z}_{\mathrm{t}, \mathrm{i}} \hat{\mathrm{N}}_{\mathrm{t}, \mathrm{i}}^{-1}
$$

which has units $\mathrm{g}$ zooplankton $\mathrm{m}^{-2} \mathrm{~s}^{-1}$. At high zooplankton densities, $\mathrm{Q}$ reaches a maximum $\mathrm{Q}_{\max }$ (Holzman and Genin 2003).

We further assume that the feeding rate of an individual planktivore is proportional to its cross-sectional area: $\mathrm{I}_{\mathrm{a}}=\zeta_{\mathrm{N}} \mathrm{L}_{\mathrm{a}}^{2} \mathrm{Q}$ (units: $\mathrm{g}$ month $^{-1}$ ), where $\zeta_{\mathrm{N}}$ is a constant of proportionality (Gurney and Nisbet 1998). This leads to von Bertalanffy growth (Gurney and Nisbet 1998) with asymptotic maximum length

$\mathrm{L}_{\infty}=\left(\eta_{\mathrm{N}} \zeta_{\mathrm{N}} \mathrm{Q}\right) /\left(\mu_{\mathrm{N}} \chi_{\mathrm{N}}\right)$,

with assimilation efficiency $\eta_{N}$, metabolic loss rate $\mu_{N}$, and length-weight proportionality constant $\chi_{\mathrm{N}}$. If individuals allocate a constant fraction $\theta_{\mathrm{N}}$ of their biomass production to reproduction $\left(\theta_{\mathrm{N}}=0\right.$ for individuals younger than the age at maturity), growth is described by

$\mathrm{L}_{\mathrm{t}+1, \mathrm{a}, \mathrm{i}}=\mathrm{L}_{\infty \mathrm{t}, \mathrm{i}}-\left(\mathrm{L}_{\infty \mathrm{t}, \mathrm{i}}-\mathrm{L}_{\mathrm{t}, \mathrm{a}, \mathrm{i}}\right) \exp \left(-\mu_{\mathrm{N}}\left(1-\theta_{\mathrm{N}}\right) / 3\right)$

Because $\mathrm{L}_{\infty, \mathrm{t}, \mathrm{i}}$ depends dynamically on $\mathrm{Q}_{\mathrm{t}, \mathrm{i}}$, which in turn depends on $\mathrm{N}_{\mathrm{t}, \mathrm{i}}$, it is possible that as population density at $\mathrm{i}$ increases, Eq. 12 could describe negative growth. This will occur when the per capita availability of zooplankton is insufficient to meet the metabolic demands of fish of size $\mathrm{L}_{\mathrm{a}}$. To prevent this biologically unlikely possibility, we impose the constraint that $\mathrm{L}_{\mathrm{t}+1, \mathrm{a}+1, \mathrm{i}} \geq \mathrm{L}_{\mathrm{t}, \mathrm{i}, \mathrm{i}}$. Whenever this constraint is enforced, we represent the effects of starvation on planktivore survival by imposing a higher predation rate $\zeta_{\mathrm{N}}{ }^{\prime}=3 \zeta_{\mathrm{N}}$ at that site for that time step (Booth and Beretta 2004). In some unusual cases (e.g. very low planktivore densities in a patch with very high zooplankton density) it is also possible for $\mathrm{L}_{\infty}$ to become implausibly large, so we constrained its value to the maximum observed for this species in captivity $\left(\mathrm{L}_{\max }\right)$.

The fecundity of each fish (eggs month ${ }^{-1}$ ) is a function of biomass production

$\mathrm{E}_{\mathrm{t}, \mathrm{a}, \mathrm{i}}=\theta_{\mathrm{N}} \mu_{\mathrm{N}} \lambda_{\mathrm{N}} \mathrm{L}_{\mathrm{t}, \mathrm{a}, \mathrm{i}}^{2}(2 \varepsilon)^{-1}$

where $\varepsilon$ is the mass of one egg and the factor 2 indicates that there is a sex ratio of 0.5 and there is no competition for mates. The total biomass or fecundity of the ith subpopulation at time $\mathrm{t}$ is the sum of $\mathrm{N}_{\mathrm{t}, \mathrm{i}, \mathrm{a}} \chi_{\mathrm{N}} \mathrm{L}_{\mathrm{a}}^{3}$ or $\mathrm{N}_{\mathrm{t}, \mathrm{i}, \mathrm{a}} \mathrm{E}_{\mathrm{t}, \mathrm{i}, \mathrm{a}}$ overall $\mathrm{A}$ age classes.

\section{Predator population}

The predator species has demographic functions generally similar to those of the planktivore (Eq. 6-8, 12-13), except that predator parameters are indexed with $\mathrm{P}$ instead of $\mathrm{N}$. We assume that predators are generalists feeding on a variety of species in addition to the planktivores in our model. This is typical of reef-based piscivores and such species are generally better represented by models lacking dynamic feedback with a single prey species (Murdoch et al. 2002). As such we do not model their energetic intake explicitly, but assume they have von Bertalanffy growth (Eq. 12) with $\mathrm{L}_{\infty}$ that is constant over space and time.

Like the planktivore, the predator suffers Beverton-Holt density-dependent mortality in the first month post-settlement (Eq. 6) followed by density-independent mortality (Eq. 8) with rate $\delta_{\mathrm{p}}$ for later ages. Unlike the planktivore, we do not consider spatial or temporal variation in either type of mortality.

\section{Zooplankton population}

We assume there is a nearshore population of zooplankton (i.e. calanoid or cyclopoid copepods) at each reef, the density of which is a factor of local oceanographic retention (Hamner and Hauri 1981). Zooplankton dynamics change on much shorter time scales that those of the higher trophic levels, so we represent them with a continuous-time logistic model:

$\mathrm{d} Z_{\mathrm{i}} / \mathrm{dt}=\rho_{0} \mathrm{Z}_{\mathrm{i}}-\rho_{\mathrm{l}} \mathrm{Z}_{\mathrm{i}}^{2}-v \mathrm{Z}_{\mathrm{i}}$,

where $\rho_{0}$ is the intrinsic biomass growth rate, $\rho_{1}$ describes density-dependent resource competition and $v_{\mathrm{i}}$ is the rate of biomass export to the reef. At equilibrium,

$Z_{\mathrm{i}}^{*}=\left(\rho_{0}-v\right) / \rho_{1}$

We assume that $v$ is constant across all locations and is equal to $\omega$, the rate of flow across the reef. As mentioned above, we consider $\omega$ to describe flows operating at a smaller spatial scale than the processes affecting larval dispersal and retention. Specifically, $\omega$ represents tidally-driven flows, such that flood tides move zooplankton across the reef, where they are consumed, and the following ebb tide returns few survivors to the offshore population (Hamner et al. 2007). Thus $\omega$ is not strictly a constant flow, but fluctuates at a time scale faster than other demographic rates so we model it as a continuous process. As noted above in 'Planktivore population', the constant flux of zooplankton across the reef is given by $\omega Z_{i}^{*}$, which we write as $\omega Z_{i}$ elsewhere for simplicity. Note that there is no feedback from planktivore consumption to the zooplankton dynamics; all copepods that travel across the reef are assumed to be eaten by some reef-based organism (Hamner et al. 2007), even when the density of our focal planktivore species is very low. Zooplankton dynamics are affected, however, by the degree of local oceanographic retention, which concentrates inorganic nutrients nearshore and relaxes intraspecific competition. We explain this relationship in the next section.

\section{Dispersal matrices}

Larval dispersal in the planktivore population is described by the matrix $\mathbf{D}$ which has elements $\mathrm{D}_{\mathrm{ij}}$ giving the probability of dispersal from patch $j$ to patch i. If we express the total fecundity of subpopulation $i$ as

$$
\mathrm{F}_{\mathrm{t}, \mathrm{i}}=\sum_{\mathrm{a}} \mathrm{E}_{\mathrm{t}, \mathrm{i}, \mathrm{N}} \mathrm{N}_{\mathrm{t}, \mathrm{i}, \mathrm{a}}
$$

then 
$S_{t+1}=\lambda_{N} D_{t}$

where $\mathbf{S}$ and $\mathbf{F}$ are row vectors with elements i for each subpopulation and $\lambda$ is larval survivorship.

The predator population has a similar dispersal matrix $\mathbf{D}^{\mathbf{P}}$ (and larval survivorship $\lambda_{\mathrm{p}}$ ), which is a linear combination of $\mathbf{D}$ and a second matrix $\mathbf{D}^{\prime}: \mathbf{D}^{\mathbf{P}}=\pi_{\mathrm{p}} \mathbf{D}+\left(1-\pi_{\mathrm{p}}\right) \mathbf{D}^{\prime}$. This represents the situation in which predator larvae are partly influenced by the same oceanographic forces that shape planktivore dispersal (D) but are also influenced by a second set of reef-based processes encapsulated by $\mathbf{D}^{\prime}$ (this formulation parallels the meaning of the parameters $\phi$ and $\psi$ in the analytical model). In theory, $\mathbf{D}^{\prime}$ could take on any form, but we assume that it is an $\mathrm{n} \times \mathrm{n}$ matrix (where $\mathrm{n}$ is the total number of subpopulations) with all entries equal to $\mathrm{n}^{-1}$. Thus $\mathbf{D}^{\prime}$ represents an equal probability of dispersal among all sites.

The parameter $\pi_{\mathrm{p}}$ quantifies the degree to which predator larvae share the same dispersal matrix as the prey; that is, it gives the degree of oceanographic coupling. The mixture of $\mathbf{D}$ and $\mathbf{D}^{\prime}$ could represent variability among larvae, such as alternative behavioral strategies (Cowen and Sponaugle 2009), or temporal variability in spawning, such as a spawning season that only partially overlaps with that of the planktivore and spans different oceanographic regimes. When $\pi_{\mathrm{P}}=1$, the predator and prey have the same dispersal matrix; when $\pi_{\mathrm{P}}=0$, predator larvae disperse uniformly among patches according to $\mathbf{D}^{\prime}$. We do not explicity model larval behavior. This does not affect the model's generality, so long as larvae of either species cannot choose to settle in a patch based on information about the community composition of that patch. In other words, we assume the probability of dispersal is not affected by the densities of predator, planktivore, or zooplankton in each patch.

Like the predator, the zooplankton have a dispersal matrix $\mathbf{D}^{\mathbf{Z}}=\pi_{\mathrm{Z}} \mathbf{D}+\left(1-\pi_{\mathrm{Z}}\right) \mathbf{D}^{\prime \prime}$. The diagonal elements of $\mathbf{D}, \mathrm{D}_{\mathrm{ii}}$, represent the probability of planktivore larvae being retained locally. This matrix element thus captures the influence of nearshore oceanographic retention. The degree of retention also strongly influences the density of nearshore zooplankton populations by increasing local nutrient densities (Wolanski and Hamner 1988). Thus the rate of intraspecific resource competition in the zooplankton, $\rho_{1}$ (Eq. 12), is inversely proportion to $\mathrm{D}_{\text {ii }}^{\mathrm{Z}}$, so we can rewrite Eq. 11 as $\mathrm{Z}_{\mathrm{i}}^{*}=\left(\rho_{0}-\right.$ v) $\rho_{Z} D^{Z}$ ii, where $\rho_{Z}$ is a constant. Thus zooplankton density ranges from zero in locations with no local retention to a maximum of $\rho_{0}-v$ in locations with $\mathrm{D}^{\mathrm{Z}} \mathrm{ii}=1$. We assume that the patches are distant enough that dispersal of zooplankton among locations is negligible, so the off-diagonal elements of $\mathrm{D}^{\mathrm{Z}}$ are set to zero. However, zooplankton can occur in large patches offshore that may span multiple reefs, so this assumption could be relaxed in future applications of this model.

\section{Modeled dispersal scenarios}

In principle we could model planktivore metapopulations with any number of subpopulations and a variety of arbitrary dispersal matrices. However, the goal of this model is to investigate the effect of oceanographic coupling on the value of patches within a metapopulation. To this end, we focused on two-patch metapopulations and two different dispersal scenarios that approximate cases in which heuristic single-population models (and our own model with no coupling; $\pi_{\mathrm{P}}=\pi_{\mathrm{Z}}=0$ ) predict that one patch should have much higher value than the other. However, the simulation model would readily scale up to a much larger number of patches, and could be made spatially realistic with the inclusion of spatial habitat data and dispersal probabilities obtained from a numerical circulation model for a specific location. We parameterized the matrices with values that would ensure unequal patch values; these examples are intended to be illustrative of actual dispersal scenarios, but are not empirically derived. For consistency, the patch with higher larval supply is always labeled patch 1.

In the downstream retention scenario, we envision patch 2 at the upstream end of a predominantly unidirectional flow field; patch 1 is downstream in the flow field but is also adjacent to an oceanographic retention zone that retains locally produced larvae and entrains those from upstream. This approximates the understanding of dispersal on the northern shore of St. Croix as well as in upwelling-relaxation systems on the Pacific Coast of North America (Hamilton et al. 2006, Diehl et al. 2007). This scenario is given by the following dispersal matrix:

\begin{tabular}{cc|cc|} 
& & \multicolumn{2}{c}{ Origin } \\
& & $\mathrm{p}_{1}$ & $\mathrm{p}_{2}$ \\
Destination & $\mathrm{p}_{1}$ & 0.9 & 0.9 \\
& $\mathrm{p}_{2}$ & 0.1 & 0.1
\end{tabular}

where destinations are along the rows and origins are along the columns (Fig. 4).

The second scenario, 'upstream retention', represents a case in which there are two patches in an advective flow field, but the upstream patch is adjacent to a retention feature. In this case, patch 1 is upstream. It retains much local production and exports the remainder downstream, whereas most larvae produced in the downstream patch 2 are lost from the system, with only a limited amount of retention and upstream export. This scenario encapsulates the idea of an 'upstream source' (Carr and Reed 1993) and is given by the following dispersal matrix (also see Fig. 4):

\begin{tabular}{cc|cc|} 
& & \multicolumn{2}{c}{ Origin } \\
& & $\mathrm{p}_{1}$ & $\mathrm{p}_{2}$ \\
Destination & $\mathrm{p}_{1}$ & 0.6 & 0.1 \\
& $\mathrm{p}_{2}$ & 0.4 & 0.2
\end{tabular}

For each scenario, we simulated metapopulation dynamics over 1000 timesteps, allowing the system to reach equilibrium, and recorded mean planktivore density in each patch over the last 100 timesteps of the simulation. We also determined patch value following the deletion index approach (White 2008), which measures the deviation in the equilibrium density of the metapopulation when patch $i$ is removed. Patch value is calculated as follows: for each patch $\mathrm{i}$, the deletion index $\mathrm{V}_{\mathrm{i}}$ is calculated by starting the system at equilibrium and then changing the planktivore dispersal matrix $\mathbf{D}$ so that all entries in row and column i are equal 

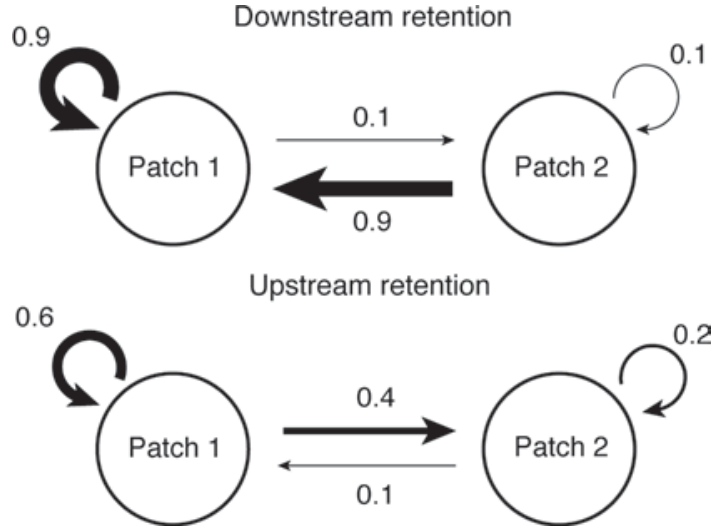

Figure 4. Schematic illustrating connectivity scenarios used in the numerical simulation model. Arrow thickness and numbers indicates probability of larval dispersal in that direction. In both cases, Patch 1 is near an oceanographic retention zone and so retains a large fraction of locally produced larvae. In the downstream retention scenario, Patch 1 also receives a large fraction of larvae produced upstream in Patch 2. In the upstream retention scenario, Patch 1 retains a slightly smaller proportion of larvae, and exports the remainder downstream to Patch 2. In that scenario, most (70\%) larvae produced in Patch 2 are swept downstream out of the system.

to zero. That is, the planktivore population at $\mathrm{i}$ is no longer connected to the other patch. The system is then run to equilibrium again with only patch $j$ (the dispersal matrices for predators and zooplankton are not perturbed). Then

$\mathrm{V}_{\mathrm{i}}=1-\overline{\mathrm{N}}_{\mathrm{j}} / \overline{\mathrm{N}}$.

Where $\overline{\mathrm{N}}$. is the mean population size in both patches (all age classes) over the last 100 timesteps in the unperturbed model, and $\overline{\mathrm{N}}_{\mathrm{j}}$ is the mean population size in patch $\mathrm{j}$ (the only remaining patch) in the model with i deleted. This statistic takes values ranging from 1 ( $\mathrm{i}$ is a global source) to 0 (mean density is the same with or without i) and less than zero (i has a negative effect on mean metapopulation density).

\section{Simulation model results}

Below, we describe the impacts of increased predatorplanktivore and planktivore-plankton oceanographic coupling on the numerical and biomass densities in each of the two patches, and quantify the relative value $V_{i}$ of each patch to metapopulation persistence.

\section{Downstream retention scenario}

In the downstream retention scenario, spatial structure in larval delivery played a primary role in determining metapopulation dynamics. The patches made proportionate contributions of larvae to the metapopulation and none of the larvae were advected out of the system. The high planktivore larval supply rate to patch 1 caused planktivore density there $\left(\mathrm{N}_{1}\right)$ to be greater than that in patch $2\left(\mathrm{~N}_{2}\right)$ under all simulated conditions (Fig. 5A-B). Because planktivore larval supply rate was disproportionately high in patch 1 , increasing predator coupling $\left(\pi_{\mathrm{P}}\right)$ caused an increase in predator density and thus predation rate on planktivores in patch 1 . Thus, we observed a gradual decline in $\mathrm{N}_{1}$ as $\pi_{\mathrm{p}}$ increased (Fig. 5A). Interestingly, biomass density $\left(\mathrm{B}_{1}\right)$ was relatively invariant with increases in $\pi_{\mathrm{P}}$ (Fig. $5 \mathrm{C}$ ), because a fixed amount of food was divided amongst a decreasing number of surviving individuals, each of which grew larger as per capita food supply (Q) increased. In contrast to the pattern in patch 1 , increased $\pi_{\mathrm{P}}$ produced a decrease in predator larval supply to patch 2, which had lower planktivore larval supply. This caused a reduction in predator density and predation rate in the low-larval supply patch 2, and a corresponding increase in $N_{2}$ (Fig. 5B). Similar to the effects in patch 1 , however, $B_{2}$ did not vary dramatically with the strength of predator coupling because a fixed amount of food was divided amongst an increasing number of surviving individuals (Fig. 5D).

Increased zooplankton coupling $\left(\pi_{\mathrm{Z}}\right)$ in the downstream retention scenario caused an increase in $\mathrm{B}_{1}$ and a decrease in $\mathrm{B}_{2}$ (Fig. 5C-D). This result was anticipated: increasing the food supply to a subpopulation (as occurred in patch 1 with increases in $\pi_{\mathrm{Z}}$ ) had a positive effect on individual growth and by extension individual and subpopulation biomass, whereas decreasing the food supply (as occurred in patch 2 with increases in $\pi_{\mathrm{Z}}$ ) had the opposite effect (recall that increased coupling, $\pi_{\mathrm{Z}}$, actually decreases zooplankton availability at the low-larval supply patch 2 ). It is worth noting that as $\pi_{\mathrm{Z}}$ rose, $\mathrm{B}_{1}$ increased at a slower rate (Fig. $5 \mathrm{C}$ ) than $\mathrm{B}_{2}$ decreased (Fig. 5D). The slower increase of $\mathrm{B}_{1}$ was due to density-dependent competition: at high numerical densities (such as those in patch 1 ), increases in $\mathrm{B}_{1}$ are limited by the amount of per capita foraging space available (because $\mathrm{Q}$, and thus $\mathrm{L}_{\infty}$, are assumed to be inversely proportional to $\mathrm{N}_{\mathrm{i}}$; Eq. 9-11). Only at low numerical densities are biomass increases limited by the maximum per capita zooplankton availability $\mathrm{Q}_{\max }$. In contrast, the decrease in $\mathrm{B}_{2}$ (Fig. 5D) was more precipitous because reductions in the food supply due to increasing $\pi_{\mathrm{Z}}$ led to starvation-enhanced predation.

Somewhat counterintuitively, numerical density declined in both patches with increasing $\pi_{\mathrm{Z}}$ (Fig. 5A-B). This pattern is less surprising, however, upon recognizing that (1) increasing $\pi_{\mathrm{Z}}$ enhanced predation (via starvation) in patch 2, causing $\mathrm{N}_{2}$ to decrease (Fig. 5B), and (2) the biomass density in each patch determined the number of larvae produced by each subpopulation, and, by extension, the number of settlers delivered to them. That is, the numerical density patterns were driven largely by changes in biomass density: as $\pi_{\mathrm{Z}}$ increased, $\mathrm{B}_{2}$ declined (Fig. 5D), in turn causing a reduction in fecundity (Eq. 12) in patch 2, and a corresponding drop in the number of settlers delivered to both patches from this upstream larval source (Supplementary material Appendix 3 Fig. 3.1).

Interpretation of the effects of the two types (planktivorepredator and zooplankton-planktivore) of oceanographic coupling is made easier by first focusing on each in isolation, but how do these two forces act together to shape subpopulation densities? While the influence of $\pi_{\mathrm{P}}$ and $\pi_{\mathrm{Z}}$ on numerical densities appear comparable (Fig. 5A-B), the effect of $\pi_{\mathrm{Z}}$ dwarfed the effect of $\pi_{\mathrm{p}}$ on biomass densities in both patches (Fig. 5C-E) (at least for the parameter values relevant to the St. Croix community; Table 2). Thus, the densities predicted for the off-axis region of parameter space in Fig. 5 generally represented the summed effects of $\pi_{\mathrm{P}}$ and $\pi_{\mathrm{Z}}$ alone: tri-trophic coupling led to reductions in patch 1 
(A)

Patch 1

(downstream; high larval supply)

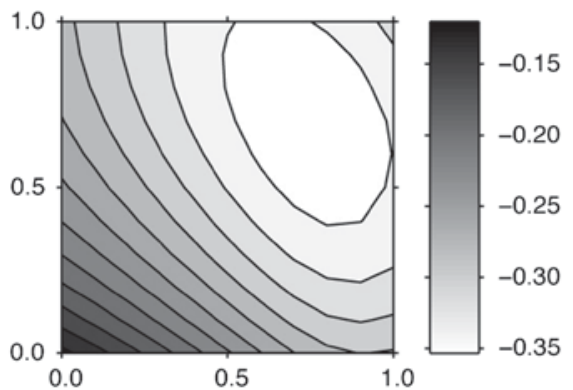

(C)

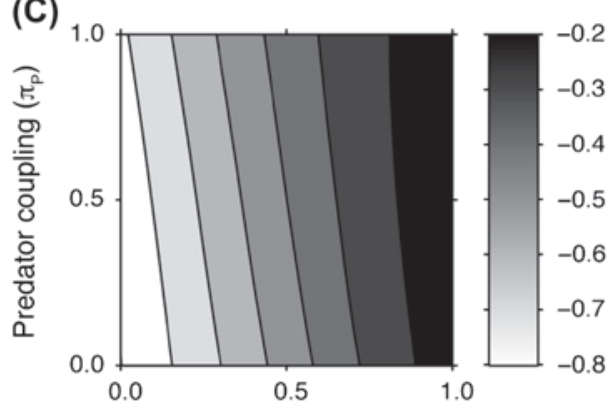

(E)

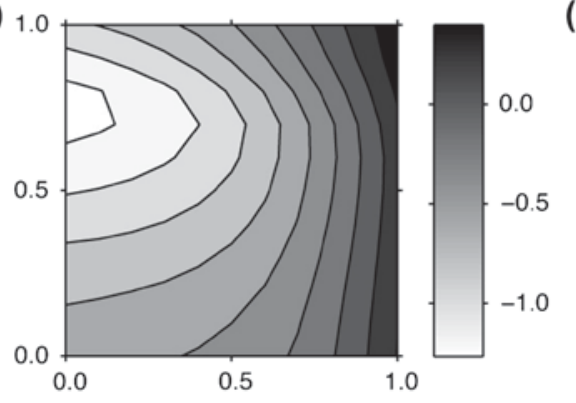

Patch 2

(B) (upstream; low larval supply)

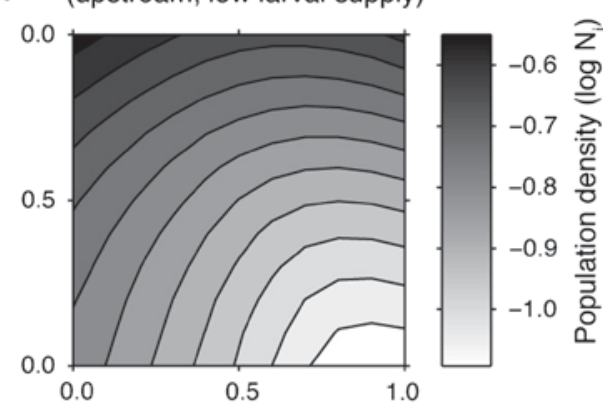

(D)

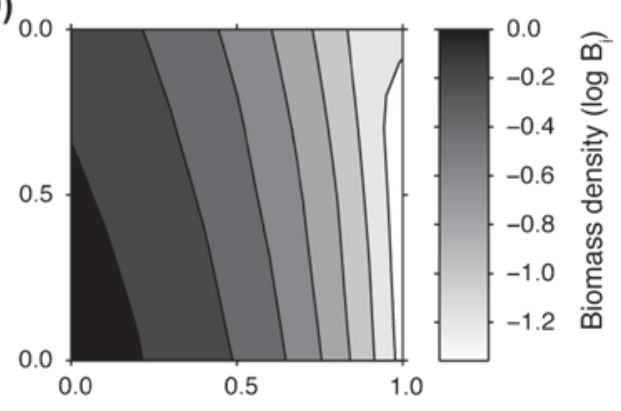

(F)

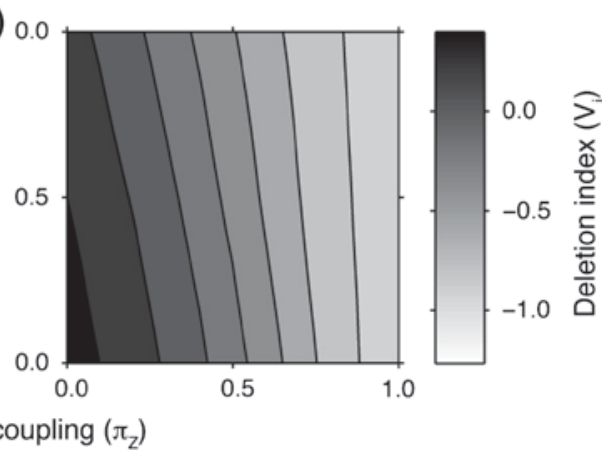

Figure 5. Results of numerical simulation model for the downstream retention scenario. Equilibrium values of (A, B) numerical density, (C, D) biomass density, and (E, F) deletion index for planktivore population in (A, C, E) Patch 1 and (B, D, E) Patch 2 for different levels of oceanographically forced coupling with predator larval supply and zooplankton abundance. Parameter values used in these simulations given in Supplementary material Appendix 2, Table A2.

population density $\left(\mathrm{N}_{1}\right)$ and patch 2 biomass density $\left(\mathrm{B}_{2}\right)$, a slight increase in patch 2 population density $\left(\mathrm{N}_{2}\right)$, and a more substantial increase in patch 1 biomass density $\left(\mathrm{B}_{1}\right)$. However in some cases the two types of coupling produced unexpected interactions. For example, at very high values of $\pi_{\mathrm{Z}}, \mathrm{N}_{1}$ did not decrease monotonically with $\pi_{\mathrm{p}}$ but actually increased somewhat at high levels of predator coupling (Fig. 5A).

A patch's value $V_{i}$ to metapopulation persistence predominantly reflected the biomass density responses to increased oceanographic coupling (Fig. 5E-F). However, the effect of $\pi_{\mathrm{P}}$ on $V_{i}$ was not completely negligible. For instance, the initial decline in $V_{1}$ with increasing $\pi_{\mathrm{p}}$ mirrored the corresponding decline in $\mathrm{N}_{1}$ rather than the increase in $\mathrm{B}_{1}$, implying an interplay between both demographic currencies in determining patch value. Nevertheless, in general the patch with the higher biomass density had a higher patch value and sustained the delivery of new individuals to the metapopulation (because of the direct link between biomass density and fecundity; Eq. 12).

\section{Upstream retention scenario}

Larval delivery to each patch was more equitable in the upstream retention scenario (Fig 4; Supplementary material Appendix 3 Fig. A1-A2), though patch 1 still received the greatest proportion. Overall metapopulation abundance was usually heavily reliant upon larval production in patch 1 because most $(70 \%)$ of the larvae produced in patch 2 were advected out of the system (Fig. 4, Supplementary material Appendix 3 Fig. A2). This larval dispersal configuration caused $N_{1} \geq N_{2}$ and $B_{1} \geq B_{2}$ at equilibrium under nearly all simulated conditions (Fig. 6).

Because the number of larvae delivered to each patch did not differ as much in this scenario as in the downstream retention scenario (Supplementary material Appendix 3, Fig. A1-A2), 
(A) Patch 1

(A) (upstream; high larval supply)

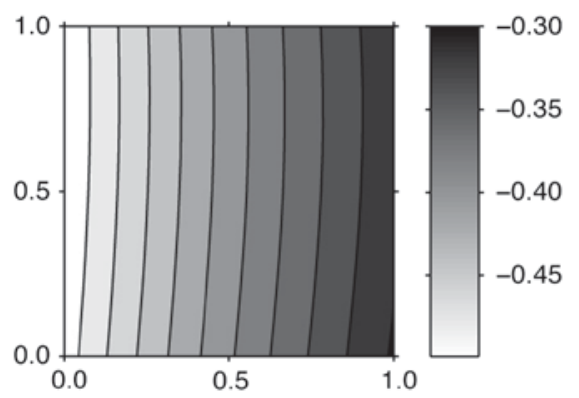

(C)

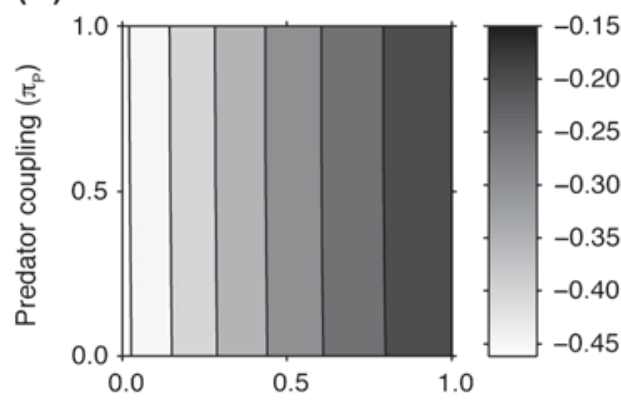

(E)

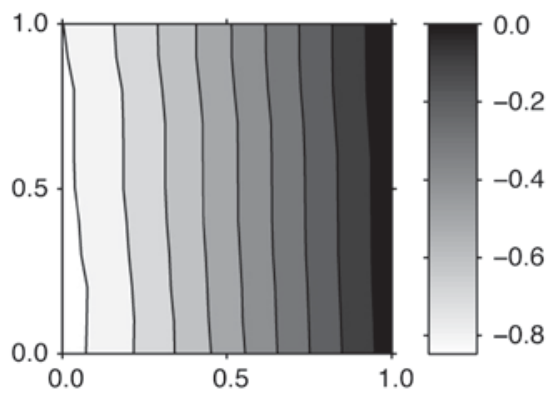

Patch 2

(B) (downstream; low larval supply)

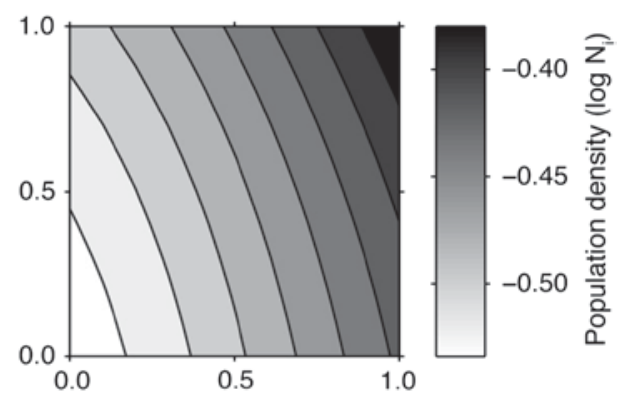

(D)

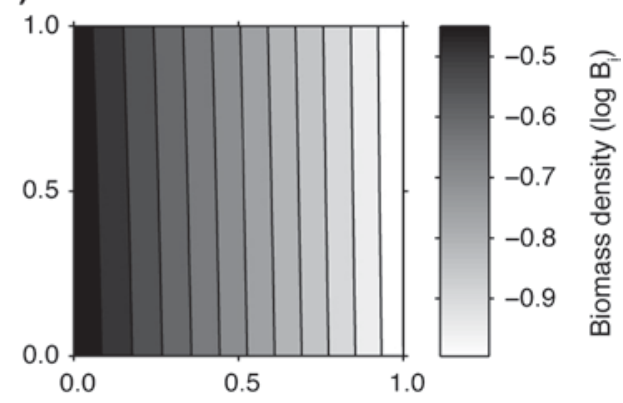

(F)

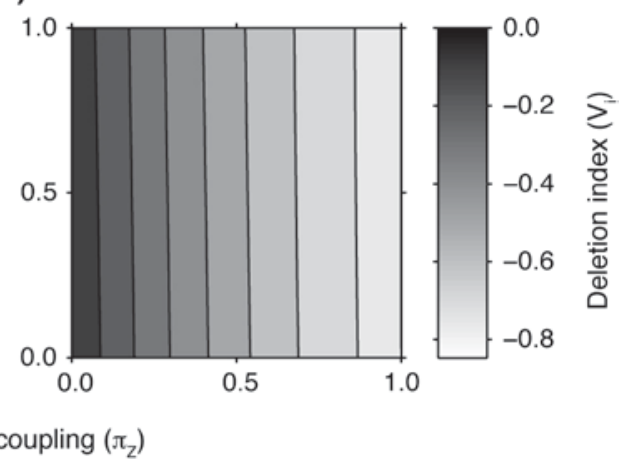

Figure 6. Results of numerical simulation model for the upstream retention scenario. Equilibrium values of (A, B) numerical density, (C, D) biomass density, and (E, F) deletion index for planktivore population in (A, C, E) Patch 1 and (B, D, E) Patch 2 for different levels of oceanographically forced coupling with predator larval supply and zooplankton abundance. Parameter values used in these simulations given in Supplementary material Appendix 2, Table A2.

the effects of predator-planktivore and planktivore-plankton coupling were less dramatic (compare vertical axes of Fig. 4 and 6). Increased predator coupling caused only slight increases in the predation rate in patch 1 and slight decreases in patch 2. These small changes in predation rate due to oceanographic coupling did not lead to substantial changes in numerical or biomass densities in either patch (Fig. 6). The most pronounced gradient instigated by increasing $\pi_{\mathrm{P}}$ was a moderate increase in $\mathrm{N}_{2}$ : survival was higher in Patch 2 with fewer predators $\left(\pi_{\mathrm{P}} \rightarrow 1\right)$.

In this dispersal scenario, increasing zooplankton coupling had a greater impact on $\mathrm{N}_{\mathrm{i}}$ and $\mathrm{B}_{\mathrm{i}}$ than increasing predator coupling because both patches received similar proportions of a common larval pool, so even with strong predator coupling there was not a large disparity in predator density or predation rates between the two patches. By contrast, most larvae successfully recruiting to one of the patches were produced in Patch 1 (because most larvae spawned in Patch 2 were advected from the system), so that changes in the zooplankton biomass available to Patch 1 planktivores had a large effect on the metapopulation. Overall, this causes the dynamics in the two patches to appear much more uniform and less variable in this scenario than in the downstream retention scenario.

As $\pi_{\mathrm{Z}}$ increased, planktivores in patch 1 were able to attain larger sizes and greater population biomass than those in patch 2 (Fig. 6C), leading to even more dramatic increases in fecundity because of its nonlinear relationship with body size (Eq. 12). As both patches relied heavily upon larval production from the upstream-source patch 1 in this dispersal scenario, increased $\pi_{\mathrm{Z}}$ boosted numerical density in both patches (Figs. 6A-B). However, increased $\pi_{\mathrm{Z}}$ simultaneously augmented $\mathrm{N}_{2}$ and reduced the food supply to patch 2, causing a decline in $\mathrm{B}_{2}$ (Fig. $6 \mathrm{D}$ ). 
In this upstream retention scenario, tri-trophic coupling led to increases in $\mathrm{N}_{1}, \mathrm{~N}_{2}$, and $\mathrm{B}_{1}$, and a decline in $\mathrm{B}_{2}$. However, the off-axis region of parameter space in Fig. 6 is influenced almost entirely by changes in $\pi_{\mathrm{Z}}$. That is, the combined effects of predator-planktivore and planktivore-plankton coupling were nearly identical to the effects of planktivore-plankton coupling alone.

As in the downstream retention scenario, a patch's value $\mathrm{V}_{\mathrm{i}}$ to metapopulation persistence was dictated by the biomass density responses to increased oceanographic coupling (Fig. 6E-F). Importantly, the upstream retention scenario differed from the downstream retention scenario in that in the former scenario population density was often actually equal to or higher in each patch in the absence of the other (i.e. $V_{i}$ was negative except for $V_{1}$ at high values of $\pi_{\mathrm{Z}}$; Fig. 6E-F). This outcome occurred because both patches had sufficiently high self-connectivity (elements $\mathrm{D}_{\mathrm{ii}}$ of the disperal matrix $\mathbf{D})$ to be persistent in isolation, and the slightly lower larval supply experienced in isolation actually produced modest increases in biomass because of reduced competition for zooplankton (cf. Fig. 5A). Nonetheless, the patch with the higher biomass density had a higher patch value than the patch with lower biomass density, and these patterns were driven by variation in the strength of zooplankton coupling, with very little influence from changes in predator coupling. Interestingly, despite patch 2's minimal contribution of larvae to the metapopulation, explicit accounting for the three trophic groups reveals that there are several parameter sets for which $V_{2}>V_{1}$ (Fig. $6 \mathrm{E}-\mathrm{F}$ ).

\section{Discussion}

Marine metacommunities are complex systems, both biologically and physically. They are characterized by ecological interactions among different combinations of species, each of which is susceptible to disturbance and dispersal forced by oceanographic processes at a range of spatial and temporal scales (Guichard et al. 2004). Models of these systems have tended to focus on either their biological complexity (assuming relatively simple dispersal patterns; Guichard 2005) or their physical complexity (ignoring species interactions; Cowen et al. 2006) but not both. Here we offer an initial heuristic analysis of potential complexities arising within a marine metacommunity when oceanographic forcing couples dynamics across trophic levels (see Figueira 2009 for a related metapopulation example). Our models suggest that single-species or multispecies models that ignore the potential for such coupling could make predictions that are systematically biased or incorrectly estimate the relative contribution of patches to metapopulation and metacommunity dynamics.

The analytical model provides a simple way to conceptualize the problem of oceanographic coupling within a tritrophic system (plankton-planktivore-predator), and can be used to make general predictions about the consequences of coupling. The basic results are relatively straightforward: for a patch that receives higher-than-average larval supply of the planktivore, increased coupling with the productivity of the planktonic resource will increase planktivore biomass relative to a model that assumes independent fluxes of the two trophic groups, and increased coupling with predator larval supply will decrease planktivore biomass relative to a model that assumes independence between planktivore and predator larval movements. The opposite patterns hold for a patch that receives lower-than-average planktivore larval supply. This relatively simple analysis provides two benefits. First, it can serve as a starting point for analyses of new systems: by gauging the type and intensity of coupling involved and whether larval supply is above or below average in a particular patch (using results like those shown in Fig. 1-2), one could estimate the degree of bias likely to be present in a single-species model (or a multispecies model that ignores coupling). An important detail in that type of cursory analysis is the relative strength of top-down versus bottom-up processes; we assumed that the former dominated in coral reef fish populations $\left(\xi \kappa_{\mathrm{p}}>>\eta \kappa_{\mathrm{Z}}\right)$ but the same will not hold in all systems. It is also worth noting that there is a line of equivalence in Fig. 3 along which coupling with both zooplankton and predators offset, and planktivore densities do not differ from the case in which there is no coupling. In other words, there may be situations in which models lacking oceanographic coupling nonetheless produce accurate results.

The second benefit provided by the analytical model is as a null hypothesis and point of departure for the more complex, system-specific numerical simulation model. The goal of the latter effort was to determine whether the analytical model predictions were robust to the more complex dispersal patterns and nonlinear interactions present in real coral reef metacommunities. In general, the analytical and numerical models make similar predictions about the effects of tri-trophic coupling on planktivore density, though the numerical model predictions are more nuanced because the perceived outcome depends on the demographic currency (numbers or biomass) under consideration (also see Sandin and Pacala 2005). The specific predictions of this analysis depend on the parameter values and dispersal scenarios chosen, and may not readily extrapolate to very different systems. Nonetheless, the overall finding that patch value $\mathrm{V}$ was well predicted by planktivore biomass B (but not numerical density N) held true across all simulations. This general relationship could be applied to empirical estimates of biomass within a relatively well-connected metacommunity in order to predict patch value in the absence of direct simulations.

While the simulation model incorporated realistic levels of spatial variability in larval supply, it was beyond the scope of this study to consider the importance of temporal variability in larval supply, current velocity, zooplankton productivity, or any of the factors that are known to vary over time in real systems. Given the potentially large consequences of variance in systems with nonlinear dynamics (Ruel and Ayres 1999), this is a worthy topic for further investigation. In the future we anticipate applying the simulation model presented here to a more specific metacommunity in which we have robust estimates of dispersal probabilities among patches (from a numerical circulation model or observation of genetic or geochemical tags in larvae; Cowen and Sponaugle 2009). In that case it would be feasible to estimate and incorporate realistic estimates of larval retention into the dispersal matrix as well as appropriate levels of temporal covariation in oceanographically-forced processes. 
The finding that patch value was better predicted by biomass density than by larval recruitment or numerical density implies that careful consideration should be given to the oft-made assumption that 'hotspots' of larval settlement or of species abundance are the most critical to metapopulation or metacommunity dynamics (Lipcius et al. 1997). For example, Caselle et al. (2003) found that numerical density of bluehead wrasse was much higher near an oceanographic retention zone (site BB in Fig. 1) than in a site with lower larval supply (site GC in Fig.1) but that total biomass density was similar at the two locations. In light of our model results, these data suggest that the two sites have similar source values despite the difference in larval supply. Note that this finding would apply to real data, but not to the predictions of single-species metapopulation models, because if the latter do not include oceanographic coupling they are likely to incorrectly estimate biomass.

Though simple, the two stereotypical dispersal matrices used in the simulation model represented a range of dispersal patterns that could occur in real metacommunities, and suggested some general conclusions regarding the dynamics of these systems. First, planktivore population dynamics exhibited strong bottom-up control despite the strong topdown control on numerical densities by predators. Indeed, we found that under a range of conditions predator coupling may have a smaller effect on planktivore biomass and patch value than oceanographic coupling with the zooplankton population (cf. Samhouri 2007). This phenomenon was observed in both the downstream and upstream retention scenarios, but likely depends on the strength of intraspecific competition in the planktivore population, which we assumed reflected competition among planktivores for feeding space within the flow-field.

The circumstances under which resource limitation has a greater impact than predator limitation in coral reef fish populations are not yet clearly defined (reviewed by Jones and McCormick 2002). In organisms thought to experience multiple sources of density dependence, often one limiting factor exerts the predominant regulating influence at a particular time or in a particular place (Belovsky and Joern 1995). In the terrestrial plant literature, resource limitation is well-recognized as the primary mechanism for limiting population biomass (law of constant final yield; Harper 1977). This effect is usually attributed to the fact that plant growth is indeterminate and fecundity is a function of plant biomass; these life history traits also apply to fishes (Samhouri and Sandin 2006). In aquatic ecosystems more generally, Osenberg and Mittlebach (1996) have suggested that resource limitation may be more severe than predator limitation across a range of trophic levels, while in temperate and tropical marine ecosystems, density-dependent growth is not uncommon (Lorenzen and Enberg 2002, Jones and McCormick 2002) and may even serve as the ultimate mechanism of density-dependent predation (Hixon and Jones 2005).

These studies from other systems lend credence to our finding that oceanographic coupling of planktivores with the zooplankton population significantly influenced patch biomass, and by extension, patch value. Importantly, however, because intraspecific competition for zooplankton causes density-dependent maturation and fecundity, its effects will be delayed compared to density-dependent predation, which causes immediate changes in population abundance on both local and metapopulation spatial scales (Jones and McCormick 2002). As we observed in our model, local changes in population biomass due to resource limitation influence population abundance primarily via changes in fecundity, which manifest effects on the spatial scale of the entire metapopulation (i.e. in terms of patch value). Theoretical explorations such as this one provide one avenue for investigating how processes that are empirically tractable on small spatial scales exhibit effects on larger spatial scales (also see Sandin and Pacala 2005, White 2008).

Second, the nature of nearshore circulation and larval dispersal can alter the relative importance of top-down versus bottom-up control. For example, planktivore density, $\mathrm{N}$, is strongly affected by the strength of predator coupling (top-down control) in the downstream retention scenario, but is much more strongly affected by zooplankton productivity (bottom-up control) in the upstream retention scenario). As a consequence, representing single-species dynamics in such systems is difficult without quantifying both intraspecific interactions and larval dispersal patterns (also see Figueira 2009). Third, the simulations revealed the importance of explicitly determining whether patches are self-persistent (White et al. 2010a): under certain conditions, it is possible for a patch to thrive in isolation because of reduced competition from settlers that would otherwise disperse from other locations (i.e. patch 2 in the upstream retention scenario).

The models presented here were motivated by empirical patterns observed in two well-studied coral reef systems. But physically-forced coupling across multiple trophic levels may be found in other systems as well, and the analytical framework we have developed could be applied more broadly. For instance, movement in riverine metacommunities is strongly affected by hydrodynamic forcing, which can concentrate both resources and organisms in downstream confluences (Power and Dietrich 2002, Hilker and Lewis 2010). Terrestrial metacommunities in vernal pools or pitcher plant leaves (Sarracenia purpurea) are linked by aerial dispersal, which is likely to be affected by wind (Miller and Kneitel 2005, Vanschoenwinkel et al. 2008). In the marine realm, oceanographic processes drive covariation across trophic levels in temperate areas such as the Galapagos (between phytoplankton, barnacles, and barnacle predators; Witman et al. 2010) as well as the Pacific coast of the United States. In the latter, the recruitment of mussel larvae (Mytilus spp.) is positively correlated over large spatial and temporal scales with phytoplankton productivity (measured as chlorophyll a), possibly due to both trophic interactions (mussels and mussel larvae feed on phytoplankton) and transport processes (the local intensity of coastal upwelling; Menge et al. 2004). There is also some evidence that the major mussel predator in that system, the sea star Pisaster ochraceus, may have a settlement pattern correlated with phytoplankton abundance (Menge et al. 2004). This type of relationship may be common in strongly advective coastal systems because circulation patterns near topographic features such as capes and headlands tend to promote larval retention and settlement (Diehl et al. 2007) and are also associated with high rates of primary productivity (Broitman and Kinlan 2006).

A major goal in this paper has been to identify the 'important' or 'valuable' patches in the metacommunity in 
light of tri-trophic coupling. This is a common goal of metapopulation studies (Ovaskainen and Hanski 2003, Figueira and Crowder 2006, Figueira 2009) and important to conservation decisions (Margules and Pressey 2000, White et al. 2010a). However, it is not obvious how best to extend this concept to a metacommunity. We adopted the perspective of the planktivore, but in practice a manager may be more interested in the higher trophic level species. This raises the question of how best to quantify the value of a patch to multiple species in a metacommunity context. In other words, what is the metacommunity equivalent of a 'source' population? While there are some examples of reserve planners attempting to account for the metapopulation structure of multiple species (Nicholson et al. 2006, White et al. 2010b), metacommunity theory has not yet grappled with the challenge of incorporating species interactions into a patch valuation framework (Guichard et al. 2004). Multispecies models such as this one (also see Guichard et al. 2004, Guichard 2005) provide an initial glimpse of the complexity of this problem.

Acknowledgements - Discussions with J. Leichter, R. Warner, $\mathrm{R}$. Vance and P. Munday were valuable in motivating this work. K. Hanson, K. Nickols and A. Stier provided insightful comments on the manuscript. This is a contribution from the Bodega Marine Laboratory, Univ. of California, Davis. JFS gratefully acknowledges support from NSF OCE 0222087.

\section{References}

Belovsky, G. E. and Joern, A. 1995. The dominance of different factors for rangeland grasshoppers. - In: Cappuccino, N. and Price, P. W. (eds), Population dynamics: new approaches and synthesis. Academic Press, pp. 359-386.

Booth, D. J. and Beretta, G. A. 2004. Influence of recruit condition on food competition and predation risk in a coral reef fish. Oecologia 140: 289-294.

Broitman, B. R. and Kinlan, B. P. 2006. Spatial scales of benthic and pelagic producer biomass in a coastal upwelling ecosystem. - Mar. Ecol. Prog. Ser. 327: 15-25.

Carleton, J. H. et al. 2001. Zooplankton community structure and water flow in the lee of Helix Reef (Great Barrier Reef, Australia). - Mar. Biol. 139: 705-717.

Carr, M. H. and Reed. D. C. 1993. Conceptual issues relevant to marine harvest refuges: examples from temperate reef fishes. Can. J. Fish. Aquat. Sci. 50: 2019-2028.

Caselle, J. E. et al. 2003. The interaction of retention, recruitment, and density-dependent mortality in the spatial placement of marine reserves. - Gulf Carib. Res. 14: 107-118.

Cowen, R. K. and Sponaugle, S. 2009. Larval dispersal and marine population connectivity. - Annu. Rev. Mar. Sci. 1: 443-466.

Cowen, R. K. et al. 2006. Scaling of connectivity in marine populations. - Science 311: 522-527.

Diehl, J. M. et al. 2007. Spatial variability of recruitment in the sand crab Emerita analoga throughout California in relation to wind-driven currents. - Mar. Ecol. Prog. Ser. 350: 1-17.

Figueira, W. F. 2009. Connectivity or demography: defining sources and sinks in coral reef fish metapopulations. - Ecol. Model. 220: 1126-1137.

Figueira, W. F. and Crowder, L. B. 2006. Defining patch contribution in source-sink metapopulations: the importance of including dispersal and its relevance to marine systems. Popul. Ecol. 48: 215-224.
Guichard, F. 2005. Interaction strength and extinction risk in a metacommunity. - Proc. R. Soc. B 272: 1571-1576.

Guichard, F. et al. 2004. Toward a dynamic metacommunity approach to marine reserve theory. - Bioscience 54: 1003-1011.

Gurney, W. S. C. and Nisbet, R. M. 1998. Ecological dynamics. Oxford Univ. Press.

Hamilton, S. L. et al. 2006. Consistent long-term spatial gradients in replenishment for an island population of a coral reef fish. Mar. Ecol. Prog. Ser. 306: 247-256.

Hamner, W. M. and Hauri, I. R. 1981. Effects of island mass: water flow and plankton pattern around a reef in the Great Barrier Reef lagoon, Australia. - Limnol. Oceanogr. 26: 1084-1102.

Hamner, W. M. et al. 1988. Zooplankton, planktivorous fish, and water currents on a windward reef face: Great Barrier Reef, Australia. - Bull. Mar. Sci. 42: 459-479.

Hamner, W. M. et al. 2007. Export-import dynamics of zooplankton on a coral reef in Palau. - Mar. Ecol. Prog. Ser. 334: 83-92.

Hanski, I. and Gilpin, M. 1991. Metapopulation dynamics: brief history and conceptual domain. - Biol. J. Linn. Soc. 42: 3-16.

Harlan, J. A. et al. 2002. Surface circulation in a Caribbean island wake. - Continental Shelf Res. 22: 417-434.

Harper, J. L. 1977. Population biology of plants. - Academic Press.

Hilker, F. and Lewis, M. 2010. Predator-prey systems in streams and rivers. - Theor. Ecol. 3: 175-193.

Hixon, M. A. 1991. Predation as a process structuring coral reef fish communities. - In: Sale, P. F. (ed.), The ecology of fishes on coral reefs. Academic Press, pp. 475-508.

Hixon, M. A. and Jones, G. P. 2005. Competition, predation, and density-dependent mortality in demersal marine fishes. - Ecology 86: 2847-2859.

Holt, R. D. 1997. From metapopulation dynamics to community structure: some consequences of spatial heterogeneity. - In: Hanski, I. and Gilpin, M. (eds), Metapopulation biology. Academic Press, pp. 149-164.

Holzman, R. and Genin, A. 2003. Zooplanktivory by a nocturnal coral-reef fish: effects of light, flow and prey density. - Limnol. Oceanogr. 48: 1367-1375.

Jones, G. P. and McCormick, M. I. 2002. Numerical and energetic processes in the ecology of coral reef fishes. - In: Sale, P. F. (ed.), Coral reef fishes: dynamics and diversity in a complex ecosystem. Academic Press, pp. 221-238.

Kent, R. et al. 2006. Preliminary evidence on group-size dependent feeding success in the damselfish Dascyllus marginatus. - Mar. Ecol. Prog. Ser. 323: 299-303.

Kiflawi, M. and Genin, A. 1997. Prey flux manipulation and the feeding rates of reef-dwelling planktivorous fish. - Ecology 78: 1062-1077.

Kingsford, M. J. and MacDiarmid, A. B. 1988. Interrelations between planktivorous reef fish and zooplankton in temperate waters. - Mar. Ecol. Prog. Ser. 48: 103-117.

Kritzer, J. P. and Sale, P. F. 2006. Marine metapopulations. - Elsevier.

Leibold, M. A. et al. 2004. The metacommunity concept: a framework for multi-scale community ecology. - Ecol Lett. 7: 601-613.

Leichter, J. J. et al. 1998. Breaking internal waves on a Florida (USA) coral reef: a plankton pump at work? - Mar. Ecol. Prog. Ser. 166: 83-97.

Leis, J. and Carson-Ewart, B. 1997. In situ swimming speeds of the late pelagic larvae of some Indo-Pacific coral-reef fishes. Mar. Ecol. Prog. Ser. 159: 165-174.

Lipcius, R. N. et al. 1997. Hydrodynamic decoupling of recruitment, habitat quality and adult abundance in the Caribbean spiny lobster: source-sink dynamics. - Mar. Freshwater Res. 48: 807-815.

Lorenzen, K. and Enberg, K. 2002. Density-dependent growth as a key mechanism in the regulation of fish populations: evidence 
from among-population comparisons. - Proc. R. Soc. B. 269: 49-54.

Margules, C. R. and Pressey, R. L. 2000. Systematic conservation planning. - Nature 405: 243-253.

Menge, B. A. et al. 2004. Species interaction strength: testing model predictions along an upwelling gradient. - Ecol. Monogr. 74: 663-684.

Miller, T. E. and Kneitel, J. M. 2005. Inquiline communities in pitcher plants as a prototypical metacommunity. - In: Holyoak, M. et al. (eds), Metacommunities: spatial dynamics and ecological communities. Univ. of Chicago Press. pp. 122-145.

Murdoch, W. W. et al. 2002. Single-species models for manyspecies food webs. - Nature 417: 541-543.

Nicholson, E. et al. 2006. A new method for conservation planning for the persistence of multiple species. - Ecol. Lett. 9: 1049-1060.

Osenberg, C. W. and Mittelbach, G. G. 1996. The relative importance of resource limitation and predator limitation in food chains. - In: Polis, G. A. and Winemiller, K. O. (eds), Food webs: integration of patterns and dynamics. Chapman and Hall. pp. 134-148.

Osenberg, C. W. et al. 2002. Rethinking ecological inference: density dependence in reef fishes. - Ecol. Lett. 5: 715-721.

Ovaskainen, O. and Hanski, I. 2003. How much does an individual habitat fragment contribute to metapopulation dynamics and persistence? - Theor. Popul. Biol. 64: 481-495.

Persson, L. and De Roos, A. M. 2006. Food-dependent individual growth and population dynamics in fishes. - J. Fish Biol. 69: $1-20$.

Power, M. E. and Dietrich, W. E. 2002. Food webs in river networks. - Ecol. Res. 17: 451-471.

Ruel, J. J. and Ayres, M. P. 1999. Jensen's inequality predicts effects of environmental variation. - Trends Ecol. Evol. 14: 361-366

Sale, P. F. 1991. The ecology of fishes on coral reefs. - Academic Press.

Samhouri, J. F. 2007. The influence of food and shelter on densitydependent process in coral reef fishes. - PhD thesis, Univ. of California, Los Angeles.

Samhouri, J. F. 2009. Food supply influences offspring provisioning but not density-dependent fecundity in a marine fish. Ecology 90: 3478-3488.

Samhouri, J. F. and Sandin, S. A. 2006. Can density-dependent fecundity regulate coral reef fish populations? - Proc. 10th Int. Coral Reef Symp. 1: 122-131.

Sandin, S. A. and Pacala, S. W. 2005. Demographic theory of coral reef fish populations with stochastic recruitment:

Supplementary material (available online as Appendix O19226 at $<$ www.oikosoffice.lu.se/appendix $>$ ). Appendix 1-3. comparing sources of population regulation. - Am. Nat. 165: 107-119.

Sih, A. 2005. Predator-prey space use as an emergent outcome of a behavioral response race. - In: Barbosa, P. and Castellanos, I. (eds), Ecology of predator-prey interactions. Oxford Univ. Press, pp. 240-255.

Sponaugle, S. and Cowen, R. K. 1997. Early life history traits and recruitment patterns of Caribbean wrasses (Labridae). - Ecol. Monogr. 67: 177-202.

Thorrold, S. R. et al. 1994a. Larval supply of shorefishes to nursery habitats around Lee Stocking Island, Bahamas. I. Small-scale distribution patterns. - Mar. Biol. 118: 555-566.

Thorrold, S. R. et al. 1994b. Larval supply of shorefishes to nursery habitats around Lee Stocking Island, Bahamas. II. Lunar and oceanographic patterns. - Mar. Biol. 118: 567-578.

Vanchoenwinkel, B. et al. 2008. Any way the wind blows frequent wind dispersal drives species sorting in ephemeral aquatic communities. - Oikos 117: 125-134.

Wainwright, P. and Bellwood, D. 2002. Ecomorphology of feeding in coral reef fishes. - In: Sale, P. F. (ed.), Coral reef fishes: dynamics and diversity in a complex ecosystem. Academic Press, pp. 33-55.

White, J. W. 2007. Spatially correlated recruitment of a marine predator and its prey shapes the large-scale pattern of densitydependent prey mortality. - Ecol. Lett. 10: 1054-1065.

White, J. W. 2008. Spatially coupled larval supply of marine predators and their prey alters the predictions of metapopulation models. - Am. Nat. 171: E179-E194.

White, J. W. and Warner, R. R. 2007a. Behavioral and energetic costs of group membership in a coral reef fish. - Oecologia 154: 423-433.

White, J. W. and Warner, R. R. 2007b. Safety in numbers and the spatial scaling of density-dependent mortality in a coral reef fish. - Ecology 88: 3044-3054.

White, J. W. et al. 2010a. Population persistence in marine reserve networks: incorporating spatial heterogeneities in larval dispersal. - Mar. Ecol. Prog. Ser. 398: 59-67.

White, J. W. et al. 2010b. Decision analysis for designing marine protected areas for multiple species with uncertain fishery status. - Ecol. Appl. 20: 1523-1541.

Witman, J. D. et al. 2010. Coupling between subtidal prey and consumers along a mesoscale upwelling gradient in the Galápagos Islands - Ecol. Monogr. 80: 153-177.

Wolanksi, E. and Hamner, W. M. 1988. Topographically controlled fronts in the ocean and their biological influence. - Science 241: 177-181. 